\title{
CORPUS BASED ANALYSIS OF FIRST-PERSON PRONOUNS IN RESEARCH PROPOSALS WRITTEN BY RUSSIAN STUDENTS
}

\author{
Ivan Grigoriev ${ }^{1}$, Alexandra Sokolova ${ }^{2}$ \\ ${ }^{1}$ St Petersburg University, ${ }^{2}$ Higher School of Economics2, Russia \\ E-Mail: i.grigorev@spbu.ru, av.sokolova@hse.ru
}

\begin{abstract}
Although displaying authorial stance is an inseparable component for AngloAmerican academic writing tradition, it seems to be problematic for those who are at the beginning of their academic writing career. The use of first-person pronouns is the most vivid principle of moving from formality and objectivity to uncovering the authorial stance and thus to involving the reader into the discussion. The paper focuses on the way novice writers use first-person pronouns for self-positioning. A corpus of Research Proposals written by Russian students majoring in five different subjects has been analyzed to establish discourse functions of first-person pronouns used, as well as to identify what has the major influence on the use of pronouns for authorial stance: disciplinary field or traditions of Russian academic writing. The research showed that socio-cultural traditions in writing influence greatly the way the students explain their position: 'polite we' not only outnumbers 'I' occurrences, but could substitute it in violation of conventions; disciplinary differences in discourse and textual features of the first-person pronoun use are not very visible but still play a part in academic writing. The findings from this research have implications for EAP curricula developers.
\end{abstract}

Key words: authorial stance, research proposal, self-positioning, academic genres.

\section{INTRODUCTION}

Globalization and internationalization of higher education establish prerequisites for every university student to master his/her skills in English for academic purposes. Norms of academic writing as well as the practical abilities to produce academic texts are of especial importance for the countries whose integration in international science has not been completed. Leaving behind grammar and lexis correctness we come to rhetorical preferences of Anglo-Saxon academic culture that includes among others text structure expression of authorial stance which, according to Wingate (2012), the focal point of argumentation is expressing the author's stance.

Research into academic writing has been focused on general features of L2 academic writing, comparative studies of L1 and L2 academic texts, and research of typical mistakes by L2 students. Apart stands analysis of hownational language, national cultural traditions and national academic conventions influence $\mathrm{L} 2$ academic texts.

It is common knowledge that displaying authorial stance is an inseparable component for Anglo-American academic writing tradition. However, there are significant differences in the way authorial stance is expressed in various national writing traditions. Thus, the studies on Slavic languages have found that there exist some similarities among academic

Submitted October $2^{\text {nd }}, 2019$, accepted for publication November $1^{\text {st }}, 2019$ 
writing styles that deviate considerably from the norm in Russian, Polish and Czech academic writing: lack of signposting and reader engagement, as well as a high degree of hedging, where the author even assumes a defensive position in expectation of criticism. Slavic writers rarely use the first-person singular for self-mention and typically use authorial plural even in the cases of single authorship as a sign of authorial modesty, unobtrusiveness and distance, as found in Russian, Bulgarian, Czech and Slovak (Walková, 2019, p. 61). Other research on L2 Russian academic texts (Yakhontova, 2006; Vasilieva 2000; Shchemeleva, 2015;Shchemeleva, Smirnova,2018) supported these conclusions and demonstrated that their authors are inclined to follow the Russian academic discourse traditions. Thus, for Russian students, who are novice L2 writers, expressing authorial stance might be quite complicated since they may be under significant influence of the national writing tradition (Connor, 1996; Fløttum et. al., 2007; Çandarlı et. al., 2015).

The genre of project proposal is one of those genres that university students have to master. According to Swales (1996), it belongs to the so-called 'occluded' genres, and unlike the Research Article genre, it has not been extensively studied in the EAP research. According to the existing studies, the main functions of the genre is to convince the reader in the quality and the validity of the proposed project, give arguments to the proposed theoretical framework and methodology (Cadman, 2002). It means that the text of the project proposal should contain a clear authorial position and students should avoid the situation when they conflate the personality of the writer with the other personalities whom they cite.

There are different approaches to authorial stance (Guinda, Hyland, 2012) and scholars used different terms to refer to authorial stance: evaluation, attitude, epistemic modality, appraisal, metadiscourse, and stance (Hyland, 2002). In this paper, we use the classification of Hyland (2005) who views authorial stance as 'community recognized personality' and "an attitudinal dimension and includes features which refer to the ways writers present themselves and convey their judgements, opinions, and commitments" (p.176). According to Hyland (2005), the authorial stance is expressed in different ways: hedges (tools like 'possible, might, perhaps' that are used to soften the categorical manner of the text and represent it rather like an opinion than like a fact); boosters (tools with a different role that highlights the author's belief that the fact provided is true, e.g. clearly, obviously), attitude markers (express the author' attitude to what has been said and the appraisal, including emotional, with the help of adjectives: remarkable, appropriate or adverbs: unfortunately, hopefully etc.) and self-mention. Since the most obvious way to express authorial stance is the use of first-person pronouns (Biber, Johansson, Leech, Conrad, \&Finegan, 1999), we look into the ways L2 writers use first-person pronouns in their texts.

First-person pronouns help the author to market themselves and their research by constructing a picture of newsworthiness and uniqueness, to link the researchers to their findings, to help the writers display their judgement while testing a hypothesis and thus to construct conversation with the reader and the academic community (Harwood, 2005).

Although for a long time the use of first-person pronoun was discouraged among the academic community (Walková, 2019, 60), central to our understanding of the role of the first pronoun is the statement of Hyland that "central element of pragmatic competence is the ability of writers to construct a credible representation of themselves and their work, aligning themselves with the socially shaped identities of their communities" (Hyland, 2002) which was then developed in other research (Flottum, 2007; Işik-Taş E.E., 2018). 
There are different classifications of rhetorical functions that first-person pronouns play in the texts. The majority of classifications stem from Hyland's five-part taxonomy:

1. Expressing self-benefits, the least powerful use of first-person pronouns used only in student writing but not in expert texts, (e.g. 'this interview is very useful both in completing our final-year report and teaching me about how to do business'); 2 . Stating a purpose, which authors use to signpost the reader through the text, (e.g. 'In this research, we deeply look at); 3 . Explaining a procedure, where the writer recounts the steps of the research process (e.g. I have collected the data); 4. Elaborating an argument, in which writers take a stance (e.g. I am purposely associating these two examples); 5. Stating results/claims, through which writers report their findings and offer their interpretation (e.g. we have now discovered) (Hyland, 2002).

The most detailed function description was given by Kuo (Kuo, 1999) to explain a procedure, propose a theory or an approach, state a goal or a purpose, show results and findings, justify a proposition, hedge a proposition or a claim, assume shared knowledge, seek agreement and cooperation, show contribution, compare approaches, give a reason, and express an expectation or a wish. In this paper, we use the terminology of Fløttum (2009) and identified the cases when the author acts as a writer, arguer, researcher, and evaluator.

The use of first-person pronouns is the most vivid principle of moving from formality and objectivity. According to Hyland \& Jiang (2017), for the period from 1965 to 2015 the frequency of the first-person use rose by $45 \%$. This field of the study is referred to as 'self-mention' and papers describe the first- person singular pronouns, first-person plural pronouns (both reader-exclusive and reader-inclusive), self-reference words such as the author(s) or the researcher(s), and sometimes even the third person pronouns to refer to the authors' own previously published work.

In our paper we investigate the most explicit way of showing the authorial stance - the use of first-person pronouns in 125 project proposals written by university students of five different disciplines. By analyzing our corpora, we answer the following research questions:

RQ 1:Which first-person pronouns are employed by the students in the project proposal genre and what are their discourse functions for their self-positioning in the texts?

RQ2:Which is the key factor for Russian students to choose the pronoun: tradition of Russian academic text (socio-cultural traditions in writing) norms and conventions of Anglo-American tradition of academic writing?

RQ 3:Are there any disciplinary differences in discourse and textual features of the firstperson pronoun use in academic writing or their use is explained by general characteristics of non-native speaker academic discourse?

Answers to these questions will help not only to show features of L2 research proposal written by Russian students, but also will become a valuable teaching resource for EAP university courses by providing comparative insights into writing practice of second language learners.

\section{METHOD}

For the analysis, we have randomly selected 25 project proposals written by Russian students from one of the leading research universities in the country, in five disciplinary fields in Social Sciences and Humanities: Economics, Logistics, Sociology, Political Science and Asian and Oriental Studies. The total number of texts is 125 , the total word- 
count is 276 423. The only criterion for the text selection was that the student had completed a course in academic writing targeted, among others, at teaching the genre of project proposal and the norms of Anglo-American academic writing.

Academic writing is a selective course offered to final year undergraduate students. It consists of 54 contact hours. During this course, the students are acquainted with the general conventions of English academic writing, the specifics of writing in their discipline and they learn how to write a project proposal. One of the topics that they study is the use of first-person personal pronoun in English academic texts. The fact that all the texts in our analysis are written by the students who studied the Academic writing course ensures that the students know the norms of the 1st person pronoun use in Academic writing in general and in their discipline in particular.

At the first stage of analysis, we counted all the cases where the first-person singular and plural pronouns and their equivalents were used. Then we excluded all the occurrences of first-person plural (we, us, our) that were used not to show the authorial position but with the purpose to engage the reader into the discussion (examples are shown in italics with the source specified in parentheses):

However, again we see the relatively old data, which do not even cover the financial crisis of 2008. (Econ014) What does the research literature in this field tell us about the object of the study? (Men013)

At the next stage of our analysis rhetorical functions of every 1st singular and plural pronoun in the texts were identified by two independent annotators. We used the classification of functions offered by Fløttum (2009). To ensure the validity of the analyses, first, we analyzed three papers and discussed every case of disagreement. After that, all the papers from one discipline were analyzed and the inter-rate agreement was calculated. Kappa coefficient is 0.74 , which is considered a substantial agreement (Landis \& Koch, 1977). After that, all texts were analyzed to identify the functions of the pronouns.

\section{RESULTS}

The frequency counts of first-person self-mention occurrences in the corpora, separately for singular, plural, singular and plural, and cases of the absence of any selfmention in the text are displayed in Table 1.

Table 1 Frequency counts of first-person self-mention occurrences

\begin{tabular}{|l|c|c|c|c|}
\hline & I & WE & I+WE & NONE \\
\hline Economics & 9 & 16 & 2 & 2 \\
Logistics & 5 & 7 & 1 & 14 \\
Management & 9 & 10 & 3 & 9 \\
Sociology & 14 & 13 & 5 & 3 \\
Oriental studies & 18 & 6 & 4 & 5 \\
\hline Total + Percentage & $55(44 \%)$ & $52(41,6 \%)$ & $15(12 \%)$ & $33(26,4 \%)$ \\
\hline
\end{tabular}

Surprisingly, $26.4 \%$ of texts included in corpora do not have self-mention at all, with logistics occupying the leading position in non-use of self-mention (56\%). Students 
prefer passive impersonal constructions. Possibly,it is explained by the risk associated with explicit pronouncing your position (Hyland, 2002).

Interestingly, $12 \%$ of RP combine the use of singular and plural pronouns which is strongly against the norm in single-authored texts:

With regards to this study, I will start with the collecting of the secondary data. ... When the data will be collecting, we can analyze it though statistic program. Moreover, we can get some basic information about the typical customer of this product. (Men014)

Possibly the Russian academic tradition to use 'polite we' plays here a part.

Frequent occurrencesof the pronoun 'we' exceedthe intuitive norms of their use, see the research proposal in management below:

For analyzing financial sides of the companies we will use profits and loses plan, income statement, balance sheet, financial plan. We will see all information, statistics and profits of companies. It will help us, when we will compare different companies: it will help us to see which company has best financial indicators. (Men002)

However, "myresearch"in the same work is not substituted for 'our research':

The result of my research will be what companies occupy top positions...

The main objectives of my research are: ...

My research shows, what competition level mobile electronic market has, ...(Men014)

Belowtheprojectproposalfromtheorientalstudiesprogrammedemonstratesthe alternating pattern in the use of singular and plural person pronouns:

The data of ourresearch are two collections of short stories and several novels have been written in the period from 1990 to 2014. After analyzing of scientific works and Chinese fiction, themes and typical characters will be distinguished.This Chinese modern fiction have been deliberately chosen because it enables us to identify how the Chinese reality, society and its problems is reflected in literature of the newest period. I will also give consideration to the role of women literature because this kind of prose has interesting specifics.(Vos008)

In the texts where both singular and plural pronouns are used by the author, we may see the disciplinary differences in the number of the first-person pronoun occurrences: the number of occurrences in oriental programme texts outnumbers plural pronouns occurrences three times. For the economics texts the statistics is diametrically opposite.

These examples prove that despite the training in academic writing students mix Russian and British-American traditions.

One more example of mixing two traditions is the prevalence of plural pronouns over singular "I" (see Table 2).

Table 2 Singular and plural pronounce occurrences in the corpus

\begin{tabular}{|l|c|c|c|}
\hline & number & I + me + my & we + us + our \\
\hline Economics & 23 & 99 & 204 \\
Logistics & 11 & 13 & 27 \\
Management & 16 & 65 & 92 \\
Sociology & 22 & 72 & 79 \\
Oriental studies & 20 & 135 & 39 \\
\hline Total & $92(73,6 \%)$ & 384 & 442 \\
\hline Number of occurrences per one text & & 7 & 17,7 \\
\hline
\end{tabular}


The data from the Table 2 show that the total number of all plural pronouns occurrences outnumbers singular pronouns occurrences (442 occurrences of 'we/us/our' against 384 of $\mathrm{I} / \mathrm{me} / \mathrm{my}$ ) and the number of plural pronouns occurrences per one text is 17.7 against seven singular pronoun occurrences.

At the second stage of our research, discourse functions of the first-person pronoun were analyzed (Table 3 ).

Table 3 Discourse functions of the first-person pronoun

\begin{tabular}{|l|c|c|c|c|}
\hline & Researcher & Arguer & Writer & Evaluator \\
\hline Economics & 177 & 34 & 25 & 5 \\
Logistics & 17 & 3 & 3 & 1 \\
Management & 82 & 4 & 3 & - \\
Sociology & 72 & 24 & 12 & - \\
Oriental studies & 81 & 21 & 9 & 2 \\
\hline Total & 429 & 86 & 52 & 8 \\
\hline
\end{tabular}

Two predominant discourse functions in the corpus are: the function of the researcher and arguer. This is true for both singular and plural pronoun (See Table 3).

The most frequent function is that of a researcher (429 occurrences):

That is why I am going to analyze not only qualitative but also quantitative data. (Soc009)

After the field stage of the study, I am planning to collect at least 15 interviews with respondents. (Soc014)

By stating his position and presenting supporting arguments the author performs the function of arguer (86 occurrences):

Looking at the category "economic and cultural capital", I can assume that parents with lower socio-economic status are interested in free of charge all educational services and try to avoid schools.... (Soc009)

Therefore, I expect that blindfolded dwellers either adapt to the circumstances and learn how to use the city using mostly common accessible information on their own or ...(Soc021)

Far less occurrences (52) we found for the authorial function as a writer who describes the structure of the project:

This chapter of the work is devoted to the data and the method .... Firstly, we briefly represent the data which is collected for the research. Secondly, we pay attention to descriptive analysis and to the causality testing for the time series data. Finally, we describe the applied approach in this work. (Econ076)

The function of assessor comprised only a small part of all the first-person uses (8 occurrences):

Aside from the relatively old datasets (the work covers the period till 2011), we are not satisfied with the choice of variables,...

The idea of this study is close enough to our investigation. Therefore, we regard this article as the most appropriate one. (Econ014) 


\section{CONCLUSIONS AND LIMITATIONS}

Representation of authorial identity in different cultures has been extensively studied for the last twenty years. This has been proven to be influenced by many linguistic and sociocultural factors which include language proficiency level and socio-cultural traditions. Attention to the problem raised students' awareness of the better ways of establishing authorial identity in different socio-cultural writing contexts. However, as our research suggests, even the course in academic writing concentrated on the ways of expressing selfmention may not bring satisfactory results. Students, in general, understand that, modern text aims at moving aside from formality and objectivity (Hyland, Jiang, 2017). Moving from formality signifies more personal approach, closer relation, and the wish to discuss expressed claims with the reader.

Mistakes found after the student's texts corpus analysis showed more similarities than differences in student's strategies to use self-mention in project proposals. Still, students make very simple mistakes using singular and plural pronouns which is strongly against the norm in single-authored texts.

Discourse functions analysis demonstrated underuse of self-mention to express assessor function. The predominance of the analyzed discourse functions seems natural and may be connected to the Russian genre conventions for academic styles, the tradition of being polite in academic papers among them.

This suggests that more training is necessary to practice rhetorical mechanisms for Russian higher education programmes. One more implication for the pedagogy is that we should be sensitive to the struggles of novice writers who are trying to combine discursive identities with disciplinary cultures, even after the specialized course in academic writing and we have to be more sensitive to rhetorical conventions of a certain genre.

This study has some limitations, which may be corrected in future research. To fully understand culturally and socially constructed view of self in Russian academic tradition more disciplinary contexts should be analyzed.

\section{REFERENCES}

Biber, D., Johansson, S., Leech, G., Conrad, S., Finegan, E. 1999. The Longman grammar of spoken and written English. London, UK: Longman.

Cadman K. 2002. English for Academic Possibilities: the research proposal as a contested site in postgraduate genre pedagogy. Journal of English for Academic Purposes, 1(2), 85-104.

Çandarl, D., Bayyurt, Y., Martı L. 2015. Authorial presence in L1 and L2 novice academic writing: Cross-linguistic and cross-cultural perspectives. Journal of English for Academic Purposes, 20, 192-202.

Connor, U. 1996. Contrastive rhetoric: Cross-cultural aspects of second language writing. Cambridge: Cambridge University Press.

Fløttum K. 2009. Academic voices in the research article Cross-Linguistic and CrossCultural Perspectives on Academic Discourse, Suomela-Salmi E., Dervin F. (eds.),

John Benjamins Publishing Company, P.109-122.

Fløttum K., Dahl T., Kinn T., Gjesdal A. M., Vold E. T. 2007. Cultural identities and academic voices. In: Language and Discipline Perspectives on Academic Discourse, Fløttum K. (ed.), Cambridge Scholars Publisher. P. 14-39. 
Guinda, C. S., Hyland, K. 2012. Introduction: A content-sensitive approach to stance and voice. In K.Hyland, C.S.Guinda (Eds.), Stance and Voice in written academic genres. (pp. 1-11). Palgrave Macmillan.

Harwood, N. 2005. 'Nowhere has anyone attempted ... In this article I aim to do just that': A corpus-based study of self-promotional I and we in academic writing across four disciplines. Journal of Pragmatics, 37(8), 1207-1231.

Hyland K. 2002. Authority and invisibility: authorial identity in academic writing. Journal of Pragmatics, 34, 1091-1112.

Hyland, K. 2005. Stance and engagement: A model of interaction in academic discourse. Discourse Studies, 7(2), 173-192.

Hyland, K., Jiang F. 2017. Is academic writing becoming more informal? English for Specific Purposes. 45. 40-51.

Işik-Taş E.E. 2018. Authorial identity in Turkish language and English language research articles in Sociology: The role of publication context in academic writers' discourse choices. English for Specific Purposes, 49, 26-38.

Ivanič, R., \& Camps, D. 2001. I am how I sound: Voice as representation in L2 writing. Journal of Second Language Writing, 10(1-2), 3-33.

Kuo, C. H. 1999. The use of personal pronouns: Role relationships in scientific journal articles. English for Specific Purposes, 18(2), 121-138.

Landis, J. R., \& Koch, G. G. 1977.The measurement of observer agreement for categorical data. Biometrics, 33, 159-174.

Schemeleva I. 2015. The revealing pronouns: the role of 1st person pronouns in defining in English and Russian research articles in sociology. In: BALEAP Biennial Conference "The Janus Moment in EAP: Revisiting the Past and Building the Future", 179-186.

Shchemeleva I., Smirnova N. 2018. Academic Writing in a Russian University Setting: Challenges and Perspectives. In: Chitez M., Doroholschi C., Kruse O., Salski Ł., Tucan D. (eds.) University Writing in Central and Eastern Europe: Tradition, Transition, and Innovation. Multilingual Education, vol 29.Springer, Cham.

Swales, J. M. 1996. Occluded genres in the academy: the case of the submission letter. In E. Ventola, \& A. Mauranen (Eds.), Academic writing: Intercultural and textual issues (pp. 45-58). Amsterdam: John Benjamins.

Vassileva, I. 2000. Who is the author? A contrastive analysis of authorial presence in English, German, French, Russian and Bulgarian academic discourse. Sankt Augustin: Asgard.

Walková, M. 2019. A three-dimensional model of personal self-mention in research papers. English for Specific Purposes, 53, 60-73.

Wingate, U. 2012. "Argument!" helping students understand what essay writing is about. Journal of English for Academic Purposes, 11(2), 145-154.

Yakhontova T. 2006. Cultural and disciplinary variation in academic discourse: The issue of influencing factors Journal of English for Academic Purposes, 5, 153-167. 